\title{
A 'sweet spot' change strategy for a least developed country: leveraging e-Government in Bangladesh
}

\author{
Shirley Gregor ${ }^{1}$, Ahmed \\ Imran $^{2}$ and Tim Turner ${ }^{2}$

\begin{abstract}
${ }^{1}$ School of Accounting \& Business Information Systems, ANU College of Business \& Economics, The Australian National University, Canberra ACT, Australia; ${ }^{2}$ School of Engineering and Information Technology, The University of New South Wales, Canberra, at the Australian Defence Force Academy, Canberra ACT, Australia
\end{abstract}

Correspondence: Shirley Gregor, School of Accounting \& Business Information Systems, ANU College of Business \& Economics, The Australian National University, Canberra ACT 0200, Australia.

Tel: +61 261253749 ;

Fax: +61 26125 5005;

\begin{abstract}
Information systems have the potential to improve societal conditions in developing countries, and yet design theory to inform interventions to encourage uptake and use of these systems is sparse. This paper reports on an action design research project that addressed the problem of limited adoption of e-Government in Bangladesh. Inadequate knowledge of the nature of e-Government systems had been identified as an underlying cause of many other problems in this 'wicked' problem context. The project aimed to reduce knowledge deficiencies among key decision makers through activities that included the delivery of a custom-made training program and a handbook targeted at senior government officers. The project had modest resources and yet yielded significant outcomes. Critical reflection established a number of design principles for a 'sweet spot change strategy' for interventions of this type, with the most important principle being to first identify a 'sweet spot', a point of maximum leverage, and then to act on it. European Journal of Information Systems advance online publication, 9 July 20 I3;
\end{abstract} doi: $10.1057 /$ ejis. 2013.14

Keywords: least developed countries; developing countries; e-Government; design science; action research; design principles

\section{Introduction}

Interventions that encourage the governments and citizens of least developed countries (LDCs) to adopt and use information systems (IS) are significant for many reasons. For one, using IS appropriately can improve economic and societal conditions for the large proportion of the world's population who live in these countries. The growing field of research that is engaged with these problems is known as information and communication technology for development (ICT4D). However, despite many initiatives by bodies such as the United Nations, the World Bank, and the European Union, many interventions designed to yield desirable improvements have had little or no lasting effect, and the knowledge building of solutions appears far from cumulative. Heeks \& Bailur (2007) characterize the problem as 'random rocks being thrown into a pool rather than building cairns of knowledge' (p. 256). The problem is serious as the development of systemized knowledge (design theory) can mean that lessons learned across projects inform subsequent interventions and reduce the chance of failure.

e-Government is a particularly important area for LDCs. Successful e-government can lead to increased compliance with international codes, norms, and standards, which means higher levels of accountability, reduced corruption, and more effective systems in important areas such as health and security (Banerjee \& Chau, 2004; Cho \& Choi, 2004; Von Haldenwang,
Received: 18 July 2011

Revised: 16 December 2011

2nd Revision: 03 June 2012

3rd Revision: 13 November 2012

4th Revision: 17 March 2013

5th Revision: 24 April 2013

Accepted: 29 April 2013 
2004; Kraemer \& King, 2006). Prior studies indicate that the use of information communication technologies (ICT) in government has flow-on effects to other sectors, which improves productivity and reduces poverty (Pilat \& Lee, 2001; World Bank, 2002; Walsham \& Sahay, 2006). According to Heeks (2003), however, 35\% of e-government initiatives in developing countries were failures (e-government was not implemented or was implemented but immediately abandoned) and 50\% were partial failures (major goals were not attained or there were undesirable outcomes). As such, for both research and practice, we need to more thoroughly understand how to achieve anticipated goals with e-government interventions in LDCs.

Some researchers see problems in theorizing in the context of ICT4D because they perceive an explosion of work on ICTs that is descriptive rather than analytical and that does not provide ground for solid theorizing (Heeks, 2006). These perceptions have arisen despite the wide range of theories that ICT4D studies include, such as actor-network theory, structuration theory, institutional theory, and innovation theory (see Stanforth, 2006; Walsham \& Sahay, 2006; Avgerou, 2008, 2009; Silva \& Westrup, 2009). Reviews in the e-government field have characterized much work as 'case stories' - event descriptions with no analyzable data or theory application (Grönlund, 2004; Norris \& Lloyd, 2006). The situation may be changing, however, as more recent attempts to address the phenomena employ different approaches. For instance, research now documents historical inventories or longitudinal analysis (Heeks \& Stanforth, 2007) and the application of different theories, such as general systems theory (Turpin et al, 2009; Wahid, 2011). Still, there has been comparatively little work that addresses the need to give interventions in LDCs a sound theoretical foundation in terms of design principles and design theory - systemized knowledge that provides a basis for design and action (Gregor, 2006; Gregor \& Jones, 2007). We develop such systemized knowledge in this paper.

The current study builds on a prior research phase (Imran \& Gregor, 2010; Imran, 2010) to: (1) design and carry out an intervention in a LDC (in this case, Bangladesh) that would assist countries to adopt e-government; and (2) reflect on the work and systemize knowledge to contribute to design knowledge in an important area of ICT4D.

We characterize our approach as action design research (ADR), a method proposed for research that sees IT artifacts as 'ensembles' with 'dimensions beyond the technological because they result from the interaction of design efforts and contextual factors throughout the design process' (Sein et al, 2011, p. 38). We situate the ADR process within a broader theorizing framework for design science research (DSR) from Lee et al (2011).

The abstract design principles that we developed form the sweet spot change strategy for LDCs (the SSC strategy). These principles resulted from reflection and analysis of experiences in a change intervention in Bangladesh in 2008, supported by the Australian Agency for International Development (AusAID) with a grant of US\$110,000. The project aimed to build capacity for e-government and ran for 12 months. Deliverables included an e-government strategy document (Imran et al, 2008), a training package, an ICT management handbook (Gregor et al, 2008), and workshops in Bangladesh. There are indications that the project had positive outcomes, which include the main stakeholders' readiness to commit to a further phase of the project.

The prime design principle that we postulate for the SSC strategy is that of 'identifying and acting on a sweet spot' that is, find a point of maximum leverage for gaining results and focus change effort on this point. The concept of a 'sweet spot' is drawn from sport in which it refers to 'the area around the center of mass of a bat, racket, or head of a club that is the most effective part with which to hit a ball' (Merriam Online Dictionary, 2011). In the economic development literature, researchers have identified a sweet spot 'zone' as a condition in which social change is especially rapid (Hughes, 2001). We identify the sweet spot as an element of, or an approach to, a change intervention that quickly delivers an effect or 'unlocks' a process of further rapid change. We describe and elucidate the further design principles of the SSC strategy in the paper's body.

The paper is structured as follows. First, we describe the relevant conceptual background. Second, we describe the research approach. In the following sections, we describe the context of the intervention, the intervention itself and its evaluation. We then elucidate design principles inherent within the intervention. Finally, we reflect on the findings.

\section{Change interventions in LDCs and the sweet spot}

This section is structured in several parts. We framed the research as an ICT intervention for a LDC, so the section begins by discussing literature relevant to ICT interventions in LDCs. Because we deliberately aimed the ICT intervention at instituting change in the LDC in the form of adoption of e-government, we briefly review the literature on adoption and change to point to fundamental theoretical ideas that informed the intervention's design. Finally, we present some further prior knowledge that informed the design of aspects of the intervention. We provide details of the theorizing process in the methods section.

\section{Theory informing interventions in LDCs}

LDCs are distinguished by the Economic and Social Council of the United Nations based on three criteria: per capita gross national income under \$905, human assets index and composite economic vulnerability index. Currently, 48 LDCs are identified (UN OHRLLS, 2012). Although our study focuses on LDCs, we have included both 'developing' and 'least developed' countries in our references to prior literature for three reasons. First, the number of studies of LDCs is limited. Second, it is believed that both DCs and LDCs share a number of common characteristics in terms of ICT adoption. Third, the word 'developing' is not used uniformly in the literature and much ICT4D work covers a range of countries that includes LDCs without explicit recognition. 
The literature on ICT4D is burgeoning. As noted above, however, concern exists about the development of cumulative knowledge and the lack of overarching theory. Nevertheless, we can draw some conclusions from this work.

Research has shown that many ICT initiatives in developing countries have been unsuccessful because they have failed to address underlying contextual issues (e.g., Heeks, 2003). Researchers struggle to find workable solutions, and practitioners largely rely on the re-use of international best practices to conserve effort and achieve results quickly. There are, however, unique factors in developing countries that must be addressed in planning information technology applications. The 'unique environment of each LDC' (Montealegre, 1999) means that 'there is no one size fits all approach' (UNDP, 2001). A particular cultural group is likely to act and behave based on their underlying values, which may be different from those of other cultural groups in similar situations (Zeffane, 1989). Ignoring these insights may result in failed systems and continued technological disadvantage (Azad et al, 1998).

Avgerou \& Walsham (2000) maintain that the design and implementation of ICT projects in developing countries must be able to address the specific contextual characteristics of the organization, sector, country, and region. Therefore, it is important to orient a design perspective to the local context through critical reflection. We can see evidence of success with such orientation in a number of past initiatives. For example, in e-government initiatives in Kyrgyzstan and Chile, user-friendly e-services were provided according to indigenous priorities (UN, 2004). Studies show that culturally appropriate IT design can enhance transfer (Straub et al, 2001), with developing countries adopting organizational designs viable in their own environment (Kim \& Utterback, 1983). Thus, a pragmatic balance between universal standards and the local context is required, with local tailoring to suit specific needs (Braa \& Hedberg, 2002; Rolland \& Monteiro, 2002; Garcia-Murillo, 2003 ).

Although many theories are included in ICT4D studies, little convergence exists about acceptable theoretical foundations for the field as a whole, especially with respect to what theory can be used as a guide to carry out change interventions. Importantly, while the ICT4D literature recognizes the importance of local context and locally designed information system solutions, few studies use design theory or design research approaches in addressing ICT4D issues. Heeks (2003) stresses that the design gap that exists between current reality and the design conceptions of western cultures accounts for the large number of ICT failures in developing countries. This gap arises when design stakeholders remain physically and psychologically distanced from the context, and contradiction occurs because of different meanings between users and designers (Heeks, 2002; Silva, 2007).

\section{Theories of innovation and change}

In this section, we discuss theory that we saw as relevant to our problem situation when the project began and that informed our overall approach. The body of theory that we identified to be most relevant was the innovation and change literature. Through the course of the project, however, it became apparent that this prior literature was lacking in the degree to which it could provide guidance. While abundant academic frameworks and literature related to organizational change in the management field are available, most of these theories, developed and tested in the developed world, have been found to be problematic in their application in the socio-cultural environment of LDCs (Chen et al, 2006).

Nevertheless, some prominent theories provide a starting point with valuable insights to investigate the innovation phenomena and change management in the LDCs. For example, Rogers' (2003) diffusion of innovations (DOI) theory shows how new innovations are adopted over a period of time. Rogers explains innovation and diffusion as a social process of communicating new ideas through certain channels over time among the members of the society. He emphasizes the role of the 'change agent' who 'influences a client's innovation decision in a direction deemed desirable by a change agency' (2003, p. 400). This theory has practical value for guiding the development of interventions, particularly in our case where the project team adopted the role of a change agent.

According to Rogers (2003), change agents provide a communication link between a resource system of some kind and a client system. They facilitate the flow of innovation from the change agency to an audience of clients. For this type of communication to be effective, the innovation must be selected to match the client's need. Furthermore, while such communication may appear to be one way, it should accommodate an effective two-way information exchange. Rogers (1995) points out that 'The long-range goal of many change agents is to create conditions in which clients can help themselves' (p. 335). Rogers identifies factors in a change agent's success, which include effort in communicating with clients, client orientation, and change-agent credibility.

\section{The sweet spot conceptualization}

The idea of a change strategy in a LDC based on a sweet spot emerged during the research. Work on the concept of a sweet spot in the academic research literature on change and innovation is limited, although the term is used by change management consultants in much the same sense that we use. For example, Norman (2003) claims that companies that used a number of innovative methodologies 'significantly enhanced the sustainable impact of their change efforts' and thus found their change management sweet spot (emphasis added).

In the economic development literature, Hughes (2001) analyzed data across a number of countries. He concludes that there was a sweet spot in the development process, which is 'a zone of GDP per capita within which social change across a wide range of individual life conditions is especially rapid' (p. 425). These individual life conditions 
include literacy rates, fertility rates, life expectancy, and food sufficiency.

Underlying theory that provides a base for the sweet spot principle lies in work on complex systems in which points of leverage are opportunities where a small shift in one thing can produce large changes in most other things (e.g., a ship's rudder). This idea can be traced back to at least Maruyama (1963), who emphasized the role of selfreinforcing cycles in complex systems and pointed out that change-magnifying cycles can have positive and negative effects. The modeling of positive and negative feedback loops continued in the field of systems dynamics (e.g., Sterman, 2000). Building on these ideas, Senge (1990), in his classic work The Fifth Discipline, argues for systems thinking in learning organizations and posits as the eighth of his 11 laws: 'Small changes can produce big results ... but the areas of highest leverage are often the least obvious' (p. 66). Meadows (1999) discusses points of leverage and positive feedback loops and suggests that three particularly effective points of leverage are the transcending of system paradigms, the mindset out of which a system paradigm operates, and a system's goals. These points of leverage resonate with our work and the development of knowledge and change in mindsets, which we identified as our point of leverage.

There has been comparatively little research related to how change agents can make use of the sweet spot concept for LDCs, although similar ideas are found in some studies such as those of complex inter-organizational systems (e.g., Gregor \& Johnston, 2001).

The work discussed above points to some key ideas in the sweet spot conceptualization. One key idea is that there are certain circumstances, characterized by points in time and positive or negative forces, in which change agent effort can bring about more substantial change than would be expected in other circumstances. A second key idea is that investigation and analysis is needed to identify the sweet spots.

\section{Further referent knowledge}

Additional justificatory knowledge (the kernel theory) informed specific components of the change intervention and is referenced when the relevant component is discussed in the paper body. The need for educating non-ICT management to understand ICT became the essential goal of the intervention. Support for a similar concept is found in the work of Peter Weill and colleagues at MIT Sloan (MIT, 2010). Thus, the structure of the training program was based around the life-cycle approach to e-government of an Australian government agency (AGIMO, 2006). Knowledge of the need for sound governance practices for ICT and senior management's awareness of ICT capabilities was also employed (Avison et al, 2006). In terms of pedagogic practice, the underlying teaching philosophy is one of constructivism and included an emphasis on adult learners (Marton \& Saljo, 1997; Merriam \& Caffarella, 1999; Gibbons \& Wentworth, 2001). The strategic pathway developed for Bangladesh drew on relevant strategy development sources (Credé \& Mansell, 1998; Labelle, 2005).

\section{Conclusions from prior work}

In summary, prior literature on work in LDCs points to the need to be sensitive to local conditions in implementing change, although theories of innovation and change also suggest factors that affect the success of change agents in general. Work in complex systems and organizational learning suggests that 'points of maximum leverage' (sweet spots) exist and can be identified so as to get maximum effect for a small amount of effort when implementing change strategies. Our review showed, however, that these ideas have not been brought together or applied in the context of change interventions in LDCs.

\section{Method}

As mentioned earlier, we characterize our research approach as ADR in an overarching theorizing framework for DSR. Elements of both action research and DSR were envisaged from the outset of the project (see Cole et al, 2005). We chose action research for our project because we were faced with an immediate problematic situation in which we proposed to intervene to bring about change. We also had to work with AusAID and partner organizations in Bangladesh with whom we had to establish an

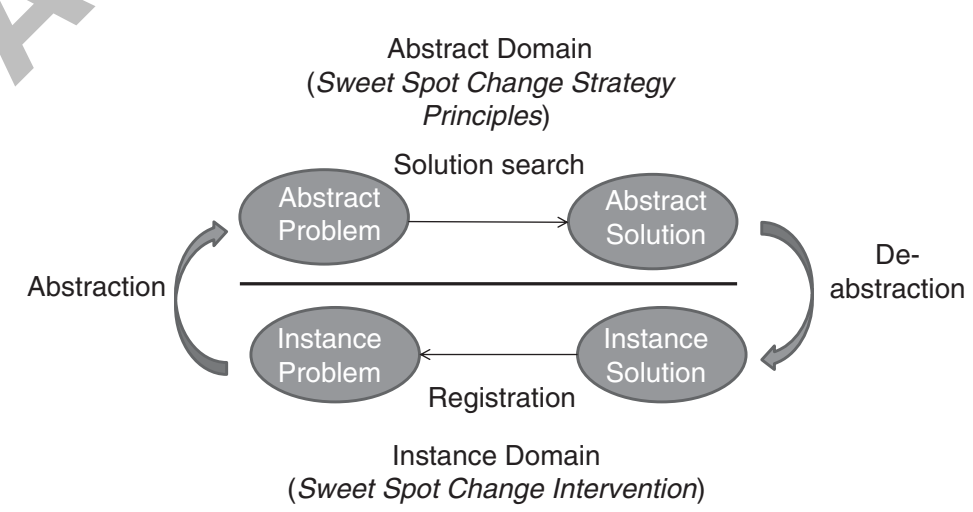

Figure 1 Design theorizing framework (adapted from Lee et al, 2011). 
ethical and feasible collaborative relationship. Furthermore, we incorporated elements of DSR because we aimed to contribute to design theory through reflection during and following our work by elucidating some general design principles (Gregor \& Jones, 2007; Peffers et al, 2008; Lee et al, 2011).

Lee et al (2011) describe the difficulties of theorizing in DSR and propose an idealized design theorizing framework that shows essential activities in a DSR theorizing process (see Figure 1). This framework provides a useful organizing device to structure discussion and terminology for distinguishing between activities that occur in an intervention and activities that occur in abstraction and theorizing.

The theorizing framework shows that theorizing occurs in two distinct domains: the abstract domain and the instance domain. In our case, the instance domain included the 'instance problem', which was the lack of adoption of e-government in Bangladesh, and the 'instance solution', which was the SSC intervention. The abstract domain includes the 'abstract problem', which for us is the problem of change interventions in LDCs, and the 'abstract solution', which is the set of SSC principles. In the 'registration process', it is necessary to show that the instance solution meets the needs of the instance problem (at least to some extent). That is, we need to show that the SSC intervention had some success in meeting the lack of adoption problem. In the 'abstraction process', the researchers derive a more generalized solution to a broader set of problems through a process that involves reflective judgment. To test the further applicability of the abstract design principles (i.e., their generalizability), it would be necessary to de-abstract and apply them in another setting. However, this further testing is beyond the scope of the current work.

The theorizing framework provides an overarching guide, and within this guide our project used ADR as a research approach. We describe the project activities using the Sein et al (2011) framework for ADR because it is a recent and useful exposition of the processes of ADR and mostly matches our research process. Sein et al (2011) show four inter-leaved stages in an integrated action research and design science process: (1) problem formulation; (2) building, intervention, and evaluation; (3) reflection and learning; and (4) formalization of learning. Stages 1 and 2 correspond approximately to the instance domain in the theorizing framework, while Stages 3 and 4 correspond more to the abstraction process leading into the abstract domain.

Table 1 shows our activities in each stage. Note that these activities did not follow in a strictly linear fashion as recognized in the iterative ADR process of Sein et al (2011) and the design theorizing framework of Lee et al (2011). Reflection and learning occurred throughout the project as would be expected in action research: some elements of the problem became clearer, and we sought evaluation and feedback at a number of points during the design of the deliverable products (strategy document, training program, handbook, and awareness activities) that were used in the intervention.
Phase 1 of the overall program of work was one of analysis and led to the uncovering of the 'sweet spot' (lack of knowledge) that was acted upon in Phase 2, with the sweet spot change intervention. Phase 1 is described in detail in Imran \& Gregor (2010) and Imran (2010). A theory-building approach was used (Eisenhardt, 1989) with data gathering through focus groups using the nominal group technique (Delbecq and Van de Ven, 1971) and interviews. The focus groups identified a number of barriers to ICT adoption in the public sector of a LDC. A process model that depicts the interrelationships between the barriers was developed in an iterative process that involved consultation with stakeholders individually and in groups.

In Phase 2, the final stage of the process included a step that is not treated in detail in the Sein and colleagues' framework, namely the means by which derivation of design principles occur. Our approach was to actively reflect on the parts of the intervention that were 'most necessary' for the project to succeed, as in the reflective judgment activity described by Lee et al (2011). That is, we performed an analysis to identify the components without which the project could not have reached its objectives and for which there were no obvious alternatives. The idea behind this approach came from Pearl (2000, p. 284), who argues that, in complex situations, there are certain conditions and actions that have a high 'probability of necessity', which reflects the absence of alternative causal processes that are capable of explaining effect. In simple terms, a mosquito bite has a high probability of necessity for an individual to develop malaria: there may be other means by which an individual can develop malaria, but their probability is very low. We justify the primary design principles as having a high probability of necessity using counterfactual arguments in subsequent discussion.

We identified high-level design principles with the assistance of Sein et al's (2011, p. 45) and Lee et al's (2011) recommendations to enhance generalization by focusing on the problem that is addressed as an instance of a class of problems. It was important that we classify our field problem as an instance of change strategy problems (and named the artifact the SSC strategy so it was clear what type of artifact it was). By doing this, we were able to separate the important principles that related to the change strategy from the potential principles that related to more specific, low-level activities that occurred in this particular instantiation (see Lee et al, 2011). For example, at one point, we had principles relating to the design of the learning materials. The specific learning program we have implemented appeared to be effective, but there are certainly other means through which knowledge enhancement (if that is a sweet spot) can be produced. The specific design of the learning program in our project was not an essential part of the higher-level SSC strategy. Similarly, we used focus group discussions with the nominal group technique and interviews to identify the sweet spot in Phase 1 (Imran \& Gregor, 2010; Imran, 2010), but it is possible that some other method could also be used to identify a sweet spot. 
Table 1 The action design research process

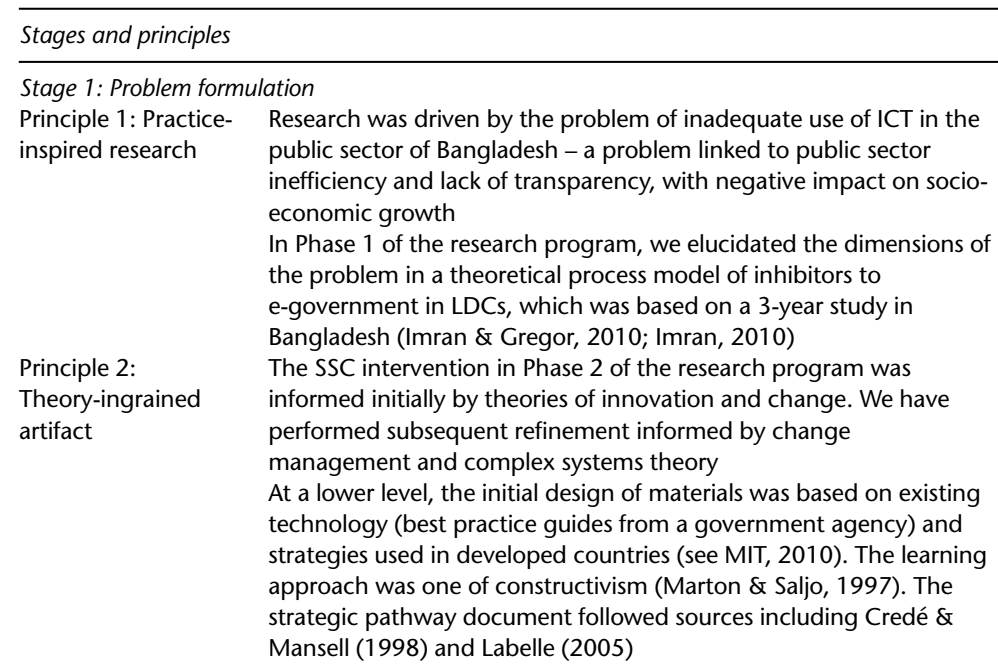

Stage 2: Building, intervention, and evaluation

Principle 3: $\quad$ A taskforce was formed with representatives from stakeholder Reciprocal shaping organizations

A strategy document, training program, handbook, and awarenessraising activities were developed and implemented. Evaluation involved counterparts and LDC recipients and included pilot testing and qualitative and quantitative data gathering

The counterpart organizations were involved with successive versions of the deliverables

Principle 4: Mutually The project team included a Ph.D. candidate with professional influential roles experience in the public sector in Bangladesh, academics with experience in industry training and innovation projects, and practitioners from counterpart organizations

Principle 5: Authentic and concurrent evaluation

Artifact

Recognition: A formal deed of agreement for Phase 2 was signed between the research group, AusAID, and counterpart organizations in Bangladesh. The activities proposed in the agreement were based on the initial theoretical understanding gained in Phase 1

$\alpha$ version: The pilot versions of the strategy document (higher-level activity) and training program and handbook (lower-level activities) $\beta$ version: The strategy document, training program, handbook, and awareness activities as delivered in Bangladesh
Stage 3: Guided emergence

Principle 6: Guided The complex nature of the deliverables and the web of surrounding emergence activities needed for their realization emerged

Stage 4: Formalization of learning

Principle 7:

Generalized

outcomes
The problem and intervention were generalized as belonging to the change strategy class of problems - the abstraction activity in theorizing (Lee et al, 2011). Principles were identified through reflective judgment that had a high probability of necessity for positive outcomes (Pearl, 2000)

A set of design principles for a sweet spot intervention was articulated and reflected upon
Emerging version and realization: The project deliverables were refined for the LDC context to gain maximum impact.

The appreciation of how the intervention was effectively achieving outcomes in the SSC strategy emerged

Ensemble version: An ensemble embodying the design principles of the SSC strategy within the LDC context emerged
At this point, we should briefly discuss the theorizing process in more detail. The prior research phase was one of analysis and the theories referred to included DOI (Rogers, 2003) and institutional isomorphism and forces (Scott, 2008). The current paper primarily deals with the second intervention phase, and here we looked more to theory that could assist with action and intervention. We acknowledge that theory evolution went hand in hand with the ADR process (see also Sein et al, 2011). Our ideas concerning the change strategy were more atheoretical at the beginning, although we conceptualized the problem in terms of 'breaking the log jam' or 'ice breaking' for e-government diffusion as informed by Rogers (2003). It was not until we were well into the second phase that we realized that what we were doing could be more appropriately conceptualized in terms of complex systems 
theory and points of leverage in self-reinforcing cycles. Our experience matches the idea of design research being a process of discovery and of theory-building through abduction, deduction, and induction (Simon, 1996; Fischer \& Gregor, 2011; Lee et al, 2011).

The artifact we developed is a change strategy - a process or method artifact - which, in the terms of Sein et al (2011), involves organization-dominant BIE (buildingintervention-evaluation) type research. Organizationdominant ADR is suited for the generation of design knowledge where 'the primary source of innovation is organization intervention' (Sein et al, 2011, p. 42). The change strategy in our project is at a higher level again than organization-dominant work because it deals with multiple public sector organizations at the national level. A number of authors now recognize the range of artifacts that can be involved in DSR. Gregor \& Hevner (2011) conceptualize the IT artifact as including both products and processes (methods) and ranging from 'technical' to 'socio-technical'. Other authors who see a management strategy/intervention as a socio-technical artifact include Carlsson et al (2011), among others.

In the following sections, we first describe the change strategy intervention and its evaluation, then the SSC principles that were abstracted.

\section{The change strategy intervention}

This section describes the intervention in terms of initial problem identification, the project initiation, and the project deliverables. Appendix A provides a timeline of these activities against the general background of e-government readiness in Bangladesh.

\section{Phase 1 - Problem definition}

Bangladesh, one of the 48 LDCs, can be characterized as a country with a high power distance. The administrative culture inherited from the colonial system has evolved into distinctive hierarchical patterns of interactions between officials and citizens, superior-subordinate relationships, and methods of government service delivery (Siddiqui, 1996; Jamil, 2007). The public administration of Bangladesh is heavily influenced by political instability and uncertainty (Jamil, 2007), which poses a threat to continuity of any institutional process. The existing bureaucratic and manual business processes in government were not conducive to high levels of citizen satisfaction or involvement and were seen to affect the overall productivity and socio-economic condition of the country.

In Phase 1 of the research program, a theoretical process model of inhibitors to the adoption of e-government in a LDC was developed The extent to which the inhibitors influenced each other (e.g., the lack of knowledge about ICT influencing the lack of adoption of solutions to technology issues) was articulated in the process model in Figure 2. This initial research proved to be a critical element of the project and underpins our primary design principle. The process is described in summary in the

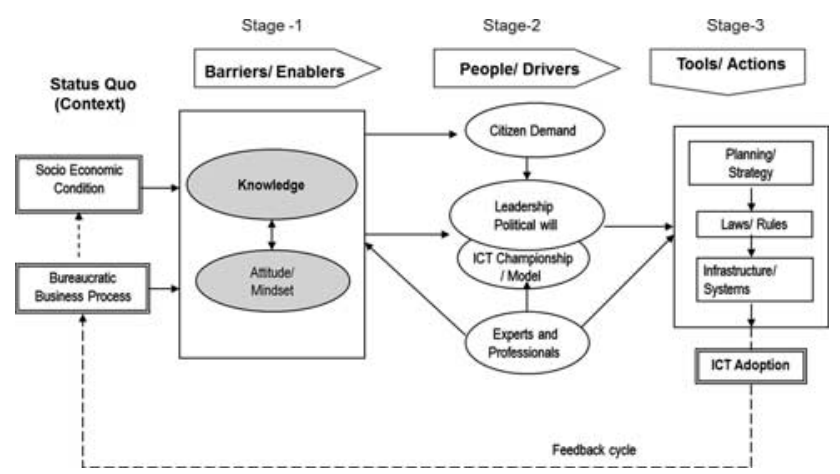

Figure 2 Process model for e-government adoption in LDCs (adapted from Imran \& Gregor, 2010).

method section and in detail in Imran \& Gregor (2010) and Imran (2010). The thorough and careful accumulation of insight into this phase revealed a critical stumbling block for successful adoption of e-government in the Bangladesh public sector - namely, that decision makers lacked fundamental knowledge and understanding of ICT, and also demonstrated a lack of awareness of the strategic use and implications of ICT systems for government business processes. This finding was significant as this lack of knowledge was found to inhibit adoption of solutions to a range of other typically identified barriers such as poor infrastructure, low socio-economic conditions, and a lack of leadership with respect to ICT. We identified the lack of knowledge and the attitudes of public sector decision makers as key barriers to address to facilitate further success in e-government initiatives.

\section{Phase 2 - The egov change project}

Against this background, we were successful in obtaining a grant for effective and sustainable e-government in Bangladesh under the auspices of a competitive grant scheme of AusAID. On the basis of the research findings described above, the project focused on the critical issue of filling the knowledge gap in e-government in a systematic way to achieve successful adoption of a broader e-government strategy for the public sector of Bangladesh.

We addressed the following questions in planning the project:

- How could 'know-how' about the effective use of ICT in public sector organizations be developed among key decision makers and government officials in Bangladesh?

- What would be the most effective tool for an initial icebreaking activity?

- How could the initial knowledge-building be replicated in a wider community?

Accordingly, after careful consideration, we planned several deliverables for the project:

- A 5-year strategy for the effective uptake of ICT and e-government in Bangladesh; 
- A training package and management handbook to build know-how and to reinforce skills transfer to the Bangladesh Government; and

- Awareness-raising activities to promote the importance of e-government.

Collaborators and participants for this initiative included an Australian government information management office and experts from Australia and Bangladesh. The counterpart public service agency of the project was the Ministry of Science and Information and Communication Technology (MOSICT) of Bangladesh. The Bangladesh Institute of Peace and Security Studies provided support as a third-party organization.

e-Government for Bangladesh: a strategic pathway to success The first project deliverable was a comprehensive report in the form of a published book (Imran et al, 2008) with a strategic direction for the next 5 years for Bangladesh. We developed the book based on the findings of the initial research and sources that propose highlevel strategies for the adoption of ICT in developing (e.g., Credé \& Mansell, 1998; Labelle, 2005).

ICT management handbook and training program: a guide for government officers of Bangladesh We developed a comprehensive, innovative training program supported by a novel handbook in collaboration with stakeholders and with pilot testing. We did not design the program to teach senior officials how to perform IT management in detail per se. Rather, we designed the program to raise awareness and show senior officials why ICT and its management are important and how to administer the whole process of ICT implementation and operation, which follows the approach of 'IT for the non-IT executive' used by researchers at MIT (see MIT, 2010). We designed the course to include sufficient references to resource materials and a reading list to allow further learning, plus an online resource. The training package includes teaching material with PowerPoint slides, exercises, quizzes with suggested answers, and videos, all of which takes two days to deliver. This package is self-contained, can be re-used over multiple offerings, and can be delivered by people other than the original developers. It comprises four modules that each have four hours of delivery.

The package is accompanied by a handbook that is structured to match the delivery modules. Expert consultants developed each module based on research findings and best practice guides, and refined them to suit local conditions through consultation and extensive local involvement. The handbook is not intended to cover everything about ICT management or to be a substitute for management training or experience, but it serves as a solid starting point for a new manager of ICT projects or a quick reference guide for more experienced managers. The document templates and checklists referred to throughout the handbook are contained in a companion workbook.
We presented the training program as a 2-day workshop in three offerings in October 2008 to a total of 107 participants, starting with 47 'e-Government Focal Points' in the first offering, which represented the 47 ministries in the Bangladesh government. We delivered the two other offerings to mid-level government officials who are expected to manage and promote e-government in their respective ministries.

In bureaucracies with a high-power distance and where junior staff are often better informed than higher-level staff because of their more recent education, the training process must be handled sensitively. Furthermore, senior government officials in Bangladesh, as elsewhere, are stretched for time, which limits their ability to learn about new innovations. Thus, we adopted a balanced approach to empower senior officials in the shortest possible time by providing 'quick win' tips and checklists presented in a concise 'lightweight' approach. We deliberately designed the handbook to fit into a coat pocket or handbag so that it could be carried at all times.

The knowledge gap of senior officers was hard to readily acknowledge because it appeared derogatory to their position and status. This problem needed careful handling to account for the strong cultural tradition through motivation and empowerment without compromising the status quo. We addressed the challenge of handling such a delicate issue through compliance with local custom and our organizational and environment knowledge of the context. The broad strategy to build motivation involved several cycles that began from convincing the top manager and then working at various levels with key influencers, sometimes through informal meetings, social connections, and peer connections. Throughout the process, it was important to build confidence that the change agents had appropriate motives and to ensure that senior officers did not feel their position and status threatened.

Awareness-raising activities We distributed some specially designed awareness posters (in Bengali) promoting an ICT-based working environment to the participating government officers to display in their office premises. The coffee mug given as memento of the training program included an ICT awareness slogan 'Use ICT to fast track your job'. We also distributed posters to government officers' training institutions - the Bangladesh Public Administration Training Centre (BPATC) and the Bangladesh Civil Service (BCS) Academy. In addition, we had interviews with the media and prepared media reports (see Appendix A).

Reflections on the intervention To conclude this section, we present our reflections on the change strategy as implemented.

(1) The recommendations in the DOI literature (Rogers, 2003) provided a useful base for change agent activities in an LDC. These recommendations informed several elements of our approach, which includes an unthreatening approach to key stakeholders with an emphasis 
on potential benefits and an empathy with their situation, as well as the awareness-raising activities.

(2) For activities designed to increase knowledge, principles of learning theory can be employed because these are expected to hold across many contexts and cultures (Marton \& Saljo, 1997; Merriam \& Caffarella, 1999; Gibbons \& Wentworth, 2001). However, learning materials, as with other interventions, should be tailored to the context (Avgerou \& Walsham, 2000).

(3) Existing technologies (best-practice guides, professional training courses) from developed countries can be utilized in the development of new artifacts (e.g., MIT, 2010) by adapting them for the context.

\section{Intervention evaluation and impact assessment}

We applied a formative evaluation approach to key elements of the project while it was underway. A formative evaluation aims to collect feedback on an intervention in progress (Trochim, 2006; Evalsed, 2009) to fine-tune the activities of the intervention and to 'ameliorate the messiness that is an inevitable part of complex, multi-faceted programmes in a fluid policy environment' (Evalsed, 2003, p. 1). At the conclusion of the main project, we conducted a more conventional evaluation. The formative evaluation of the intervention took a variety of forms, including workshops in which we presented plans for the project for discussion and sought feedback from stakeholders, observation, feedback forms at the training sessions, scrutiny of reports of the program and related material in the media, and informal feedback by email and in interviews. Follow-up evaluation occurred 18 months after the project concluded. We kept a project logbook to document observations, evaluation, and design decisions as they occurred. Appendix A provides further relevant information in the timeline of activities and change. Appendix B provides evidence of the project's worth from sources that include evaluation activities in training workshops, media reports, feedback from the funding agency, and in follow-up evaluation.

Further compelling evidence for the worth of the overall strategy comes from the ongoing change activities that the project has leveraged. The handbook enjoyed some popularity. We distributed all 300 copies from the initial release and there has been continuing demand. Many senior officers who were unable to attend the training program requested copies of the books and some bought extra copies for their department. On the basis of this demand, MOSICT reprinted another 500 copies of the handbook at its own cost. Expressions of interest have been received from several agencies including the central government agencies to translate the copy of the handbook into Bengali to achieve greater dissemination. Translation of this book into Bengali is currently underway by the Bangladesh Computer Council.

The research is now in its third phase, in which we are assisting the BPATC to institutionalize e-government knowledge through a newly developed comprehensive course curriculum. BPATC is the apex training institute that trains the officers of government, autonomous and nongovernment organizations, and all new entrants to the BCS. This phase is being implemented in three stages, and builds on the previous work with a wider focus. In addition to the development and delivery of the e-government management course curriculum, we are developing a textbook on e-government to suit the particular context of LDCs.

More generally, recognition of the importance of ICT in the government sector of Bangladesh is increasing, with a number of initiatives and projects found across ministries and agencies. The current government has an agenda for Digital Bangladesh by 2021 (Mursalin, 2009). It is difficult to establish any strong causal links between a specific project such as ours and a high-level change in a complex socio-technical environment. We do, however, believe that our project has contributed to these ICT initiatives (see Appendix A).

\section{Design principles for the sweet spot change strategy}

In this section, we present the design principles that we identified as the key factors responsible for the positive outcomes from the project, congruent with the abstraction process in the theorizing framework (Figure 1). Presenting these principles and the underlying grounding in the kernel theory potentially allows the specifics of this project to be translated into future interventions in LDCs. The principles and the kernel theory are mandatory components of a design theory as specified by Gregor \& Jones (2007), and are cast in a format adapted from the work of Dr Ed Lewis (pers. comm.). Table 2 shows each principle in summary form, while the rationale for each principle and its grounding and implications are provided below. The support for each principle is also included. We note again Sein et al's (2011, p. 44) comment that it is difficult to provide controlled evaluation in an ADR project, but rather that 'authenticity' is the important ingredient. The evidence presented in Appendix B indicates that, in general, the intervention had positive outcomes and that AusAID and the Bangladeshi stakeholders regarded the intervention as a success.

All the principles are interlinked and are seen as necessary components of the SSC strategy. Principle 1, however, is the primary principle, with the other principles representing supporting principles to accomplish the primary principle in the LDC context.

\section{Principle 1: Identify and act on the sweet spot(s)}

Rationale: While an intervention in an LDC is likely to have a constellation of inhibitors to address, there will likely be one or two underlying causes or concerns (the sweet spot) that prevent other larger and more obvious inhibitors from being addressed. In the Bangladesh project's case, the key inhibitor was identified as a lack of knowledge and senior decision makers' concomitant attitude toward ICT in the Bangladesh public sector. If such a sweet spot is identified and addressed, the remainder of the 
Table 2 SSC strategy for LDC design principles

\begin{tabular}{ll}
\hline Principle 1 & $\begin{array}{l}\text { Identify and act on the sweet spot(s) } \\
\text { Undertake a thorough analysis to identify the primary } \\
\text { underlying inhibitor(s) for a desired outcome and } \\
\text { target the initial intervention activity to address and } \\
\text { overcome the primary inhibitor(s) } \\
\text { Engage influential stakeholders } \\
\text { Principle 2 } \\
\text { An intervention in an LDC should seek to multiply its } \\
\text { effect by engaging highly influential participants } \\
\text { Principle 3 } \\
\begin{array}{l}\text { Local knowledge is mandatory } \\
\text { Intervention projects must include team members } \\
\text { from the LDC }\end{array} \\
\text { Tailor the intervention to suit the LDC with existing } \\
\text { knowledge as a base } \\
\text { Any intervention should be tailored to address the } \\
\text { specific requirements for the country, which are } \\
\text { identified after careful investigation. Best practice, } \\
\text { knowledge, and theory from other contexts can be } \\
\text { used as an initial base for artifacts and activities } \\
\text { comprising an intervention }\end{array}$ \\
\end{tabular}

intervention will be more effective because overcoming other inhibitors will be facilitated and a positive reinforcing cycle of change encouraged.

Grounding: We earlier described the theoretical underpinnings of the sweet spot concept (Maruyama, 1963; Senge, 1990; Meadows, 1999). This concept does not, however, appear to have been earlier applied in ICT4D or elucidated in the form presented here.

Implications: This principle's most important implication is the need to search for the primary underlying inhibitor(s) of a desired outcome in each unique LDC context and then use that inhibitor as a 'point of leverage'. This process may also surface issues that have been obscured because of superficial analysis or judgments. It is likely that the search for primary inhibitors will require extensive analysis. If the investigation and analysis is thorough and credible then results can be used to convince key stakeholders of the worth of the change strategy (see Principle 2).

Evaluation: We argue that the scale of the successful outcomes of the project compared with the limited budget and resources that were available is evidence of the success of this strategy. Other much larger and better-funded projects could not point to a similar degree of success.

\section{Principle 2: Engage influential stakeholders}

Rationale: An ambitious bottom-up approach that targets most of a LDC's population can be less effective than a highly leveraged one. For example, it is almost an impossible task to meaningfully target the $162+$ million people in Bangladesh. In the LDCs, a majority of the population is under the poverty line, deprived of education and knowledge, and is heavily dependent on government or their leaders (UN OHRLLS, 2012). A top-down approach can be effective in bringing about change - a single good government decision affects millions in a LDC.
Grounding: This principle is compatible with Rogers (2003) innovation theory where he stressed the mobilization of 'opinion leaders' through whom DOI is more likely to be successful. While a common success factor in developed-country ICT projects (Beath, 1998), the enlistment of key stakeholders is seen as particularly important in the LDC context. In a collective culture, which is typical of LDCs, people generally follow the direction that their leaders set for them. It is thus important to educate or empower decision makers first because, through their decisions in policy and implementation, they can significantly impact millions. In theoretical terms, they possess the 'power' to exert coercive, normative, and mimetic pressures (Scott, 2008) on the organization and citizens to encourage innovation and diffusion. Research also shows that creating champions among government officials in many other developing countries can create significant impact (Wilson, 2004).

Implications: One of this principle's key implications is that senior decision makers must be convinced of the importance of their role in the intervention, even when the ultimate effect is aimed at others (e.g., lower-level employees, others external to the organization, and citizens). A strength of our project was that one team member had been employed in the Bangladesh public sector and was able to present compelling grounds for cooperation by key stakeholders in terms that were meaningful to them. Our project also aligned itself with felt pressures in the environment, which includes formal government policy and demands from local businesses and citizens for more modern approaches. We were able to make a strong case that receiving the knowledge would return substantial benefits to the recipients directly and their country more broadly.

Evaluation: The counterpart organizations included leaders who had influence in government circles and who were able to obtain involvement from government agencies to encourage attendance at the initial training offering. These organizations also supplied the training facilities and otherwise supported the project. The counterfactual argument is that the training program could not have proceeded without this support.

\section{Principle 3: Local knowledge is mandatory}

Rationale: The depth of local knowledge required both for initially identifying sweet spots and for successfully intervening, which includes engaging influential local stakeholders, can likely only occur when the team includes one or more team members who are natives of the LDC. As discussed above, in our project, cultural sensitivity and appropriateness was facilitated because a lead researcher was a Bangladeshi. This researcher's reputation, trust, and working experience in the local context were immensely valuable. The key stakeholders from the counterpart organizations were also closely involved as members of the project taskforce.

The effort to include one or more team members with appropriate skills who are (or were) citizens of the target 
country will be rewarded by the additional sensitivity with which the research can be conducted. This is particularly important in the initial phase that seeks the sweet spot. Often the issue that is underlying other inhibitors is culturally and even regionally specific. Such subtleties are more often recognizable by members of the culture or region than by outsiders, no matter how earnest they are. Furthermore, in-depth cultural knowledge is needed to overcome sensitive issues such the knowledge gap of senior officers, which is difficult to readily acknowledge.

Grounding: This principle parallels Rogers' (1995) recommendations that change agents should have credibility and a client orientation, but goes further in that it says the change agents must include local members.

Implications: Project teams must strive to engage and involve individuals who are native to the target LDC. Maintaining a high level of involvement by the recipient country's nationals will likely add to project costs due to travel to and from the recipient country. Training in particular skills or knowledge for local team members may be a further cost.

Evaluation: Our experience shows that the appreciation of the subtleties of the local culture would not have been possible without the inclusion of a Bangladeshi member of the project team. Similarly, we would not have been able to enlist the counterpart organizations' involvement in the project without the personal contacts and knowledge of this team member. Without these counterpart organizations being involved, we could not have proceeded with the project.

\section{Principle 4: Tailor the intervention to suit the LDC with} existing knowledge as a base

Rationale: In our project, we borrowed the concept of educating non-ICT management to understand ICT from the work of Peter Weill and his colleagues at MIT (2010) Sloan. We based the structure of our training program around the life-cycle approach to e-government of an aid country coordinating government agency, and we used both learning theory and innovation theory. However, we tailored and adapted these ideas to suit the local context, with local case studies and pilot testing with Bangladeshi participants to ensure that our materials were suitable. We designed the handbook to meet the need of a concise reference that suited the context.

Grounding: The kernel theory that supports this principle comes from the work in the ICT4D literature that shows how interventions based uncritically on practices, systems, and values from one culture will likely not translate directly to another culture (e.g., Avgerou \& Walsham, 2000). Note that ideas from developed countries were useful but they needed to be adapted to the context. The differences between the issues and objectives of LDC ICT implementations and those in developed countries are not so large that a clean slate is a worthwhile starting point. Consequently, we advocate drawing on methods and design patterns tried and tested in a developed country context to maximize the potential for success on the project and optimize the return on investment, provided that the base knowledge is critically refined via the lens of the recipient country.

Implications: The primary implication here is that an intervention can re-use existing materials when re-use is accompanied by an iterative process of continuing consultation and pilot testing. There are further implications in the need for local involvement (see Principle 3).

Evaluation: The formative evaluation of the deliverable products showed that the products became progressively more acceptable the more they were adapted for the target environment. Given our limited resources, however, we needed to re-use existing artifacts (such as the e-government life cycle from a government agency) where possible rather than start from scratch. Qualitative feedback from the participants at the training programs indicates that they appreciated the inclusion of local case stories and material. Overall, it appears that the products were fit for purpose as evidenced by the positive results from the training program and the continuing demand for the handbook.

\section{Discussion and conclusions}

\section{Overview}

In this project, we undertook an intervention in a LDC to facilitate the uptake of e-government in a problem situation that was characterized by complexity and the unstructured and uncertain nature of the problem situation - a 'wicked problem' (see Mason \& Mitroff, 1973). The project built on research that developed a causal map of interrelated factors influencing e-government adoption and identified a lack of knowledge of ICT among influential decision makers as a 'root cause' of other inhibitors (Imran \& Gregor, 2010; Imran, 2010). AusAID funded the ADR intervention, which was extremely modest in terms of size, project duration, and amount of funding $(\$ 110,000)$. In these circumstances, we designed the intervention to directly address the perceived root cause of other problems and thus gain maximum effect with the available limited effort using the sweet spot or point-of-leverage principle. The intervention involved a strategy analysis and a training program with support material that was targeted at senior government officers and ICT awareness-raising activities. There are indicators that the intervention had some success. A number of high-level design principles were elucidated based on experience and critical reflection.

\section{Limitations}

The study has some limitations. We were unable to evaluate the training program and materials as fully as we would have liked. Furthermore, action research by its nature means that the researchers are intimately involved with the subject matter of the research, and their ability to step back and critically appraise the project can be limited. We are fortunate that the AusAID has funded a further phase of the intervention to allow us to more fully evaluate 
our earlier work, to further refine the design theory, and to extend our activities. In this third phase, we will investigate further uptake of e-government in projects initiated by participants in training programs.

\section{Further work}

We have deduced the SSC principles from experiences and evidence in one ADR project, with support from prior theory. To test the generalizability of the principles, it would be necessary to apply them in a different context in the de-abstraction process shown in the theorizing framework (Figure 1). This opportunity remains for further work. It is possible also that the SSC strategy principles have applicability outside the LDC context, but this possibility also remains for future work.

\section{Conclusions}

The project has led to the elucidation of a number of design principles for an effective intervention in an LDC where a problem situation is complex and the aim is to achieve maximum effect with a limited amount of resources. We believe that these design principles, coupled with the kernel theory that gives support for each, contribute to a nascent design theory for change interventions in a LDC.

The high-level principles, with supporting the kernel theory, are:

(1) Identify and act on a sweet spot(s). This principle is supported by ideas in systems theory that posit the existence of a point of leverage (a sweet spot) that provides for maximum effect with minimum effort in a complex system (Senge, 1990; Meadows, 1999).

(2) Engage influential stakeholders. This principle has support from two sources: the DOI literature (Rogers, 2003) and the IS management literature (Beath, 1998). The principle appears to be especially pertinent in LDCs where there is a culture with high-power distances.

(3) Local knowledge is mandatory. This principle is congruent with Rogers' $(1995,2003)$ recommendations that change agents should be able to empathize with clients and have credibility in their eyes. The argument for this principle is strong in the LDC context where non-local change team members may find it difficult or impossible to gain sufficient understanding and credibility in a culture different from their own.

(4) Tailor the intervention to suit the LDC with existing knowledge as a base. This principle is congruent with prior work in DCs and LDCs that argues that interventions must address the contextual characteristics of the local environment (Avgerou \& Walsham, 2000), which implies that adapting materials is needed if they are re-used.

Although a number of these principles draw on existing theories, we believe that the presentation of these principles in combination for a change strategy represents a novel contribution for change strategies in the LDC context. The important idea that has been crystallized in this project is represented by our prime design principle: identify and act on the sweet spot(s). In this case, we identified the sweet spot as the lack of appropriate knowledge about the gains that could be achieved by using ICT and about how ICT should be managed in a government organization. While the points-of-leverage idea exists in complex systems theory, it has not been situated earlier in the context of a change strategy for a LDC. In this sense, the SSC strategy represents a step toward a mid-range theory that gives guidance for practical action, as opposed to a highlevel theory such as complex systems where the level of abstraction makes direct applicability difficult (Merton, 1968).

The project demonstrated the efficacy of an approach that blends action research and design science, which is seen in the perspectives offered by Cole et al (2005) and Sein et al (2011). The action research aspect allowed the team to undertake the intervention and respond to local conditions and factors that could only be identified when operating 'on the ground' and in collaboration with stakeholders. The DSR aspect allowed the formulation of design principles that have potential application in other situations. The research approach is similar to what Sein et al (2011) refer to as organization-dominant ADR. The project shows, however, how the ADR approach can be used with a real-life problem that encompasses multiple organizations at the level of an entire country. Furthermore, within the theorizing framework of Lee et al (2011), we engaged explicitly in a critical reflective activity using counterfactual arguments to identify key design principles that had the highest probability of necessity (Pearl, 2000). As such, this study offers an important methodological contribution.

The application of a disciplined research approach, combined with sound theoretical foundations and thoughtful reflection, have created new design principles for the wicked problems of intervening in a LDC, with a particular focus on implementing e-government. We have conducted the research that underlies the new design principles over several years and tested the theory on the ground with positive indicators of success evident. This research and its impact are ongoing. This paper offers the nascent design theory as a guide for other teams intervening in LDCs to promote project success by focusing their energy to obtain optimum effect.

\section{Acknowledgements}

The authors acknowledge the contributions of AusAID, the Australian Agency for International Development, which was the funding body for the project. However, the views expressed in the paper are those of the authors, and do not reflect the views of AusAID. Support was also obtained from the Research School of Accounting and Business Information Systems at the Australian National University and many other willing contributors. An earlier expression of some of the ideas in this paper appeared in Gregor et al (2010). 


\section{About the Authors}

Shirley Gregor is the foundation Professor of Information Systems at the Australian National University, Canberra. Her current research interests include the strategic use of information technology, intelligent systems, humancomputer interface issues, and the philosophy of technology. She is currently Editor-in-Chief of the Journal of the Association for Information Systems.

Ahmed Imran is an Information Systems Researcher whose research interests largely emerged from his personal experience in e-government in developing countries. His research has been successfully applied in Bangladesh through an AusAID project, which received the Vice Chancellor's award for Community Outreach at the Australian National University in 2010.

Tim Turner has been involved in the IT industry for over 20 years. He has played significant roles in several of Australia's leading e-government projects and regularly consults to peak bodies in the e-government arena. He is a Senior Lecturer in information systems at UNSW Canberra, at the Australian Defence Force Academy.

\section{References}

AGIMO. (2006) ICT Investment Framework. [WWW document] http:// www.finance.gov.au/budget/ict-investment-framework/index.html (accessed 22 April 2013).

AVGEROU C (2008) Information systems in developing countries: a critical research review. Journal of Information Technology 23(3), 133-146.

AvGEROU C (2009), 6-28 May) Discourses on innovation and development in information systems in developing countries' research. Paper presented at the 10th International Conference of the IFIP 9.4 working group on Social Implications of Computers in Developing Countries Dubai, UAE.

AVGerou, C and WALSHAM, G (Eds) (2000) Information Technology in Context: Studies from the Perspective of Developing Countries. Ashgate Publishing, Aldershot, UK.

AVISON D, GREGOR S and WILSON D (2006) Managerial IT unconsciousness. Communications of the ACM 49(7), 88-93.

AZAD AN, ERDEM AS and SALEEM N (1998) A framework for realizing the potential of information technology in developing countries. International Journal of Commerce and Management 8(2), 121-133.

BANDURA A (1997) Self-Efficacy: The Exercise of Control. W. H. Freeman, New York.

BANERJEE P and CHAU P (2004) An evaluative framework for analysing e-government convergence capability in developing countries. Electronic Government 1(1), 29-48.

BEATH C (1998) Supporting the information technology champion. MIS Quarterly 15(3), 355-372.

BRAA J and HEDBERG C (2002) The struggle for district-based health information systems in South Africa. The Information Society 18(2), 113-127.

CARLSSON S, HENNINGSSON S, HRASTINSKI S and KELlER C (2011) Developing design theory for IS governance and management: the case of IS integration in mergers and acquisitions. Information Systems and e-Business Management 9(1), 109-131.

CHEN YN, CHEN HM, HUANG W and CHING RKH (2006) E-government strategies in developed and developing countries: an implementation framework and case study. Journal of Global Information Management 14(1), 23-46.

$\mathrm{CHO}$ YH and CHOI B (2004) E-government to combat corruption: the case of Seoul metropolitan government. International Journal of Public Admin istration 27(10), 719-735.

Cole R, PURAO S, Rossi M and SEIN M (2005) Being proactive: where action research meets design research. Proceedings of the 26th International Conference on Information Systems, pp 325-336, Las Vegas, USA.

CREDÉ A and MANSELL R (1998) Knowledge Societies in a Nut Shell IDRC and the UN Commission on Science and Technology for Development. Oxford University Press, Oxford, UK.

DELBECQ A and VAN DE VEN A (1971) A group process model for problem identification and program planning. The Journal of Applied Behavioral Science 7(4), 466

EISENHARDT K (1989) Building theories from case study research. Academy of Management Review 14(4), 532-550.

Evalsed. (2003) Evaluating Socioeconomic development, Sourcebook 2: methods and techniques. [WWW document]http://ec.europa.eu/ regional_policy/sources/docgener/evaluation/evalsed/index_en.htm (accessed 11 November 2012).

Evalsed. (2009) 'Formative evaluation'. [WWW document] http:// ec.europa.eu/regional_policy/sources/docgener/evaluation/evalsed/ glossary/glossary_f_en.htm\#Formative_evaluation (accessed 28 May 2012).

FISCHER C and GREGOR S (2011) Forms of reasoning in the design science research process. In Lecture Notes in Computer Science (JAIN H, SINH A and VITHARANA $P, E d s)$ Service-oriented perspectives in design science research (6th DESRIST) pp 17-31, Springer, Milwaukee, MI.

GARCIA-MURILLO M (2003) Patchwork adoption of ICTs in Latin America. The Electronic Journal of Information Systems in Developing Countries 15(1), 1-9.

GIBBONS HS and WENTWORTH GP (2001) Andragogical and pedagogical training differences for online instructors. Online Journal of Distance Learning Administration 4(3), http://www.westga.edu/ distance/ojdla/ fall43/gibbons_wentworth43.html.

GREGOR S (2006) The nature of theory in information systems. MIS Quarterly 30(3), 611-642.

GREGOR S and HEVNER A (2011) Introduction to the special issue on design science. Information Systems E-Business Management 9(1), 1-9.

GreGOR, S, IMRAN, A and TURNER, T (Eds) (2008) ICT Management Handbook: A Guide for Government Officers in Bangladesh. National Centre for Information Systems Research, Canberra, Australia.

GREGOR S, IMRAN A and TURNER T (2010) Designing for a 'sweet spot' in an intervention in a least developed country: The case of e-government in Bangladesh. Proceedings of SIG GlobDev Third Annual Workshop, Association of Information Systems, Saint Louis, USA, 12 December.

GREGOR S and JOHNSTON RB (2001) Theory of interorganizational systems: industry structure and processes of change. Thirty-Fourth Annual Hawaii International Conference on System Sciences (HICSS-34), IEEE, Los Alamitos, CA.

GREGOR S and JONES D (2007) The anatomy of a design theory. Journal of the Association of Information Systems 8(5), 312-335.

GRÖNLUND $\AA$ (2004) State of the Art in e-Gov Research - A survey. In Lecture Notes in Computer Science. Electronic Government. v3183, pp 178-185, Springer.

HEEKS R (2002) Information systems and developing countries: failure, success and local improvisations. The Information Society. v18, n2, Taylor \& Francis.

HEEKS R (2003) Most egovernment-for-development projects fail: how can risks be reduced? UK: University of Manchester. IDPM i-Government Working paper no.14. http://unpan1.un.org/intradoc/groups/public/ documents/NISPAcee/UNPAN015488.pdf.

HEEKS R (2006) Theorizing ICT4D Research. Information Technologies and International Development 3(3), 1-4.

HEEKS R and BAILUR S (2007) Analyzing eGovernment research: perspectives, philosophies, theories, methods, and practice. Government Information Quarterly 24(2), 243-265.

HEEKS R and STANFORTH C (2007) Understanding e-Government project trajectories from an actor network perspective. European Journal of Information Systems 16(2), 165-177. 
HUGHES BB (2001) Global soccial transformation: the sweet spot, the steady slog, and the systemic shift. Economic Development and Cultural Change 49(2), 423-458.

IMRAN A (2010) Information communication technology adoption in governments of the least developed countries: a case study of Bangladesh. Unpublished PhD Thesis, The Australian National University.

IMRAN A and GREGOR S (2010) Uncovering the hidden issues in e-government adoption in a least developed country: the case of Bangladesh. Journal of Global Information Management 18(2), 30-56.

IMRAN A, TURNER T and GREGOR S (2008) eGovernment for Bangladesh: A Strategic Pathway for Success. National Centre for Information Systems Research, The Australian National University, Canberra, Australia.

JAMIL I (2007) Administrative Culture in Bangladesh. A H Development Publishing House, Dhaka.

KIM $L$ and UTTERBACK JM (1983) The evolution of organizational structure and technology in a developing country. Management Science 29(10), 1185-1197.

KRAEMER K and KING J (2006) Information technology and administrative reform: will e-government be different. International Journal of Electronic Government Research 2(1), 1-20.

Labelle R (2005) ICT Policy Formulation and e-Strategy Development: A Comprehensive Guidebook. Asia-Pacific Devleopment Information Programme, Bangkok.

LeE J, PRIES-Heje J and BASKerville R (2011) Theorizing in design science research. In Lecture Notes in Computer Science (JAIN H, SINH A and VITHARANA P, Eds) Service-oriented perspectives in design science research (6th DESRIST) pp 1-16, Springer, Milwaukee, MI.

MARTON F and SALJO R (1997) Approaches to learning. In The Experience of Learning: Implications for Teaching and Studying in Higher Education (Marton F, Hounsell D and ENTWISTLE N, Eds) 2nd edn, Scottish Academic Press, Edinburgh.

MARUYAMA M (1963) The second cybernetics: deviation-amplifying mutual causal processes. American Scientist 5(2), 164-179.

MASON RO and MITROFF II (1973) A program for research on management information system. Management Science 19(5), 475-487.

MEADOWS D (1999) Leverage Points Places to Intervene in a System, Hartland, VT.

Merriam Online Dictionary. (2011) Sweet Spot. [WWW document] http:// www.merriam-webster.com/dictionary/sweet\%20spot (accessed 10 November 2011).

MerRIAM SB and CaffarelLA R (1999) Learning in Adulthood. Jossey-Bass, San Francisco.

MERTON RK (1968) Social Theory and Social Structure. Free Press, New York.

MIT. (2010) Transforming your business through IT (formerly IT for the non-IT executive). Executive Education [WWW document] http:// mitsloan. mit.edu/execed/coursedetails.php?id=766 (accessed 12 April 2010).

MONTEALEGRE R (1999) A temporal model of institutional interventions for information technology adoption in less-developed countries. Journal of Management Information Systems 16(1), 207-232.

MURSALIN TE (2009) Towards Vision2021 of a Digital Bangladesh. The Financial Express. http://www.thefinancialexpress-bd.com/2009/02/ 08/58247.html.

NORMAN M (2003) The change management sweet spot, perspectives: insights for today's business leaders. [WWW document] http://wwW .sibson.com/publications/perspectives/Volume_11_Issue_2/e_article00 0162551.cfm (accessed 10 November 2011).

NORRIS DF and LLOYD BA (2006) The scholarly literature on e-government: characterizing a nascent field. International Journal of Electronic Government Research 2(4), 40-56.

PeARL J (2000) Causality. Cambridge University Press, Cambridge, UK.

Peffers K, Tuunanen T, Rothenberge M and Chatterjee S (2008) A design science research methodology for information systems research. Journal of MIS 24(3), 45-77.

PILAT D and LEE FC (2001) Productivity Growth in ICT-Producing and ICT-Using Industries: A Source of Growth Differentials in the Oecd? OECD, Paris.

ROGERS EM (1995) Diffusion of Innovations. Free Press, New York.

ROGERS EM (2003) Diffusion of Innovations, 5th edn, Free Press, New York.
ROLLAND HH and MONTEIRO E (2002) Balancing the local and the global in infrastructural information systems. The Information Society 18(2), 87-100.

ScoTT WR (2008) Institutions and Organizations: Ideas and Interests. Sage, California.

Sein MK, Henfridsson O, Purao S, Rossi M and Lindgren R (2011) Action design research. MIS Quarterly 35(1), 37-56.

SENGE PM (1990) The Fifth Discipline: The Art and Practice of the Learning Organization. Currency Doubleday, New York.

SIDDIQUI K (1996) Towards Good Governance in Bangladesh: Fifty Unpleasant Essays. University Press Limited, Dhaka.

SIMON H (1996) The Sciences of the Artificial, 3rd edn, MIT Press, Boston.

SILVA L (2007) Institutionalization does not occur by decree: institutional obstacles in implementing a land administration system in a developing country. Information Technology for Development 13(1), 27-48.

SILVA L and WESTRUP C (2009) Development and the promise of technological change. Information Technology for Development 15(2), 59-65.

STANFORTH C (2006) Using actor-network theory to analyze e-government implementation in developing countries. Information Technologies and International Development 3(3), 35-60.

STERMAN D (2000) Business Dynamics Systems Thinking and Modeling for a Complex World. Irwin McGraw-Hill, Boston.

STRAUB D, LOCH KD and HILL CE (2001) Transfer of information technology to the Arab world: a test of cultural influence modeling. Journal of Global Information Management 9(4), 6-48.

TROCHIM WMK (2006) 'Introduction to evaluation' research methods knowledge base. [WWW document] http://www.socialresearchmethods.net/ $\mathrm{kb} /$ intreval.php (accessed 28 May 2012).

TURPIN M, PHAHLAMOHLAKA J and MARAIS M (2009) The multiple perspectives approach as a framework to analyze social systems in a developing country context. Paper presented at the 10th International Conference on Social Implications of Computers in Developing Countries, Dubai, United Arab Emirates.

UN. (2004) Global eGovernment Readiness Report 2004 - Towards Access for Opportunity. Department of Economic and Social Affairs, Division for Public Administration and Development Management, United Nations.

UN. (2008) The United Nations e-Government Survey 2008: From eGovernment to Connected Governance. Department of Economic and Social Affairs Division for Public Administration and Development Management. United Nations, New York. http://unpan1.un.org/ intradoc/groups/public/documents/un/unpan028607.pdf.

UN. (2010) United Nations Global e-Government Survey: Leveraging $e$-Government at a Time of Financial and Economic Crisis, United Nations, New York. http://www2.unpan.org/egovkb/documents/2010/E_Gov_ 2010_Complete.pdf.

UN OHRLLS. (2012) List of LDCs: United Nations Office of the High Representative for the least developed countries. The criteria for the identification of the LDCs. [WWW document] http://www.unohrlls.org/ en/ldc/164/ (accessed 21 May 2012).

UNDP. (2001) Making new technologies work for human development. Human Development Report. United Nations, New York. http://www .undp.org/hdr2001.

Von HALDENWANG C (2004) Electronic government (e-government) and development. The European Journal of Development Research 16(2), 417-432.

WAHID F (2011) Explaining history of egovernment implementation in developing countries: an analytical framework. Paper presented at the EGOV IFIP International Federation for Information Processing.

WALSHAM G and SAHAY S (2006) Research on information systems in developing countries: current landscape and future prospects. Information Technology for Development 12(1), 7-24.

WILSON EJ (2004) The information revolution and developing countries. MIT Press, London.

World Bank. (2002) The eGovernment Handbook for Developing Countries. Center for Democracy and Technology, World Bank. http://www. eldis.org/static/DOC11473.htm.

ZEFFANE R (1989) Computer use and structural control: a study of Australian enterprises. Journal of Management Studies 26(6), 621-648. 


\section{Appendix A}

Table A1 Timeline of project activities against observations of national context

\begin{tabular}{ll}
\hline Activities & National context \\
\hline $\begin{array}{l}\text { Before intervention (2004-2005) } \\
\text { Problem investigation }\end{array}$ & Bangladesh rated 159th in global e-government readiness index among 192 member states (UN, \\
& 2004) \\
Imran (2010) reported in Bangladesh public sector: & $\bullet$ ICT was a low priority on the government agenda; \\
& $\bullet$ Many e-government initiatives failed to achieve success; \\
& $\bullet$ Non-ICT people thought ICT was not their business; \\
& $\bullet$ A sharp techno-centric view, with focus on hardware for ICT development
\end{tabular}

Preliminary activities (2005-2008)

Seminars conducted to draw attention to issues

News articles published (19 July 2007, 21 July 2007,

26 October 2008) (references withheld)

Interviews on Bangladesh television (21 December

2007)

Roundtable meeting with ICT stakeholders and

journalists (29 February 2008)

Intervention (2008)

Launch ceremony with high commissioner and senior officials in attendance

Strategy document released (Imran et al, 2008)

Roundtable seminar with national politicians on the role of political leadership in ICT diffusion in the country (arranged for the first time in Bangladesh)

e-Government handbook produced (300 initial copies and reprint of 500 copies)

Training program with 3 course offerings to 107

government officers

Awareness-raising activities

Seminar with political leaders to discuss issues (18 July 2008)

Further activity (2009 to date)

Follow-up data collection and publication of initial

findings (references withheld)

In response to demand, an initiative is currently

underway to have the handbook updated and

translated to Bengali

Funding obtained for follow-on activity of

institutionalization of e-government knowledge

facilitation with training courses at BPATC and

development of e-government textbook for developing

countries
Interest of media and feedback at seminars indicated that (Project Logbook, 18 July 2007):

- Some were not ready to give up the techno-centric approach;

- Some surprise at focus on ICT management; and

- Some change in opinion was underway
Bangladesh improved to 142nd in global e-government readiness index (UN, 2008) Political parties included ICT in their election agenda: for example, Digital Bangladesh Vision 2021. (http://www.digitalbangladesh.gov.bd/blog.php?ID=22)

Bangladesh Computer Council organized a computer fair with the theme 'Digital Bangladesh' Some successful ICT initiatives: for example, Voter Id card project, Chittagong port automation

\section{Appendix B}

\section{Evaluation of the SSC intervention}

Evaluation took several forms, as described below.

\section{Training workshops}

The 2-day presence and participation of senior government officials throughout the first program offering demonstrated the sense of engagement created by the specifically adapted program. As is typical with senior bureaucrats in high power distance hierarchies, many participants indicated before commencing the first offering that they might not be able to remain for more than a few hours. However, once the program started, none of them left; indeed, many cancelled their day's agenda by phone. Formal and informal feedback from this cohort indicated that the customized design of the training, targeted at Bangladeshi issues and with real-life case studies relevant to day-to-day government tasks, was particularly valued. The training sessions included much discussion about the application of concepts in Bangladesh at the time.

After the initial offering, our training hosts were inundated with requests for positions on the further training program offerings because our initial training cohort influenced subordinates to attend the workshop after returning to their workplaces. This effect multiplied after the second offering. Unfortunately, we were oversubscribed for the latter training courses by as much as a factor of three and could not service the demand. 
Some participants from this training program later stated that they always carry the handbook and read it whenever they get time. The following unsolicited email was provided to one of the authors after the training programs were completed:

The management team and facilitators devised the programme in a manner where participants found room for proactive participation as well as given a scope to understand the status of governmental efforts in Bangladesh at the moment and the priority areas which needed to be addressed and visited to mitigate potential gaps and/or to combat the challenges of the day. In addition, the compilation of thematic proceeds was a unique effort too which, in fact, came out with a very handy booklet. This handbook will help the participants and the ICT policy makers and process implementers in Bangladesh in performing their duties with confidence. (pers. corr. 2009)

We obtained both quantitative and qualitative data pertaining to the effects of the training program from surveys administered before and following each offering of the program, in addition to suggestions for improvement.

\section{Analysis of surveys from training sessions}

The surveys administered before and after training sessions included questions relating to individual's self-efficacy with respect to ICT management. Self-efficacy concerns people's beliefs in their capabilities to produce given attainments and is typically measured as a degree of confidence in one's ability (Bandura, 1997). We assessed confidence (self-efficacy) with survey questions such as 'How confident are you that you understand the governance of IT?' measured on a five-point scale from 'not at all confident' to 'very confident'. Table B1 shows the differences between pre- and post-training scores for the first offering (data gathering in subsequent offerings was incomplete). We also asked questions about the participant's intentions to promote and champion ICT in their workplace. An example question is 'To what extent do you intend to support/promote the use of IT in your organization?', measured on a five-point scale from 'very little extent' to 'very great extent'. Table B2 shows the differences between pre- and post-training scores on these behavioral intention scores.

Table B1 shows that confidence in ICT management understanding increased significantly in all areas except understanding of the e-government life cycle, which was possibly a concept that was too abstract and advanced to be fully absorbed in a short period. Table $\mathrm{B} 2$ shows that intentions with regard to ICT leadership were, on average, more positive after the training, though the differences between pre- and post-program scores were not significant.

\section{Media reports}

The strategy document (Imran et al, 2008) received a very positive reception at the highest levels of government, made clear in the remarks of the Chief Guest at its launch, the Honorable Special Assistant to the Chief Advisor (Minister in Charge): 'This approach of training first and make them knowledgeable and then implementing the program is the right approach ... it is the successful approach and I'm very glad to see this approach has been taken ...' (Project Notebook, 18 October 2008).

The strategy document and its supporting project were mentioned in the Bangladeshi press a number of times and

Table B1 Confidence in ICT management

\begin{tabular}{|c|c|c|c|c|c|c|c|}
\hline \multirow[t]{2}{*}{ ICT management competency area } & \multicolumn{3}{|c|}{$n>$ Pre-training } & \multicolumn{2}{|c|}{ Post-training } & \multirow[t]{2}{*}{$t$} & \multirow{2}{*}{$\frac{P \text {-value }}{\text { (two-tailed) }}$} \\
\hline & & Mean & $S D$ & Mean & $S D$ & & \\
\hline eGov life cycle & 48 & 3.69 & 0.971 & 3.69 & 0.926 & 0.000 & 1.00 \\
\hline IT governance & 48 & 3.38 & 1.044 & 3.79 & 0.967 & -3.411 & 0.001 \\
\hline Business case for IT & 48 & 2.77 & 1.077 & 3.48 & 1.010 & -4.669 & 0.000 \\
\hline Basics of IT procurement & 47 & 2.87 & 1.135 & 3.51 & 0.856 & -4.162 & 0.000 \\
\hline IT project management & 48 & 2.83 & 1.059 & 3.65 & 0.812 & -5.496 & 0.000 \\
\hline IT performance management & 48 & 3.19 & 1.104 & 3.88 & 0.937 & -5.419 & 0.000 \\
\hline Managing the operations of IT & 48 & 2.94 & 0.976 & 3.44 & 0.848 & -3.502 & 0.001 \\
\hline How to realize benefits from IT & 48 & 3.31 & 1.035 & 3.88 & 0.841 & -4.345 & 0.000 \\
\hline Overall & 48 & 3.14 & 0.850 & 3.66 & 0.716 & -6.239 & 0.000 \\
\hline
\end{tabular}

Table B2 Intentions for ICT leadership

\begin{tabular}{|c|c|c|c|c|c|c|c|}
\hline \multirow[t]{2}{*}{ Leadership area } & \multirow[t]{2}{*}{$n$} & \multicolumn{2}{|c|}{ Pre-training } & \multicolumn{2}{|c|}{ Post-training } & \multirow[t]{2}{*}{$t$} & \multirow{2}{*}{$\frac{\text { P-value }}{\text { (two-tailed) }}$} \\
\hline & & Mean & $S D$ & Mean & $S D$ & & \\
\hline Create or strengthen partnerships/alliances with IT people in your organization & 47 & 3.79 & 1.318 & 4.13 & 0.947 & -1.663 & 0.103 \\
\hline Promote/support the use of IT in organization & 47 & 4.23 & 1.068 & 4.36 & 0.942 & -0.643 & 0.523 \\
\hline Overall & 47 & 4.01 & 1.144 & 4.245 & 0.820 & -1.274 & 0.209 \\
\hline
\end{tabular}


in the aid country press, indicating that we were attracting attention through our supportive counterpart organizations. The Minister for ICT was seen openly carrying his copy of our handbook to an important meeting on ICT in Bangladesh, exactly the 'handy pocket reference' status we had hoped for (Project Notebook, 20 January 2009).

\section{Funding agency}

The project had a positive assessment from the AusAID, demonstrated by the funding of a follow-on project in the highly competitive grant scheme in 2010 (out of 37 applications, only 6 were funded in this round).

The AusAID South Asia Director in an open forum termed this activity as one of their 'best sellers' among the public service initiatives where it is often difficult and challenging to achieve success. He further noted, 'The level of commitment in this project was noticed by us which was significant and that was reflected in the outcomes too. ... The use of funding in such a creative way was terrific and it does take a lot of effort to build this relationship not only with the Australian National University but also between Australia and Bangladesh' (Project Notebook, 27 August 2010).

\section{Follow-up evaluation from first phase}

To gauge ongoing outcomes from the first phase of the project, we performed further evaluation 18 months after its completion. Six face-to-face interviews with senior participants who are still in their same work role were carried out in June and July 2010. The interviews were recorded, transcribed, and analyzed using qualitative methods.

The findings show evidence of a transformation of mindset among some senior government officials. As stated by one interviewee, the program was the original sprit and encouragement for taking ICT seriously (Interview C, 7 July 2010). One senior participant commented:

What I feel is that, our eyes were opened in that workshop in respect of using ICT in government office, specially the managing of e-Gov in Bangladesh. (Interview A, 22 June 2010)

A senior officer who was found actively leading a new e-government initiative within his ministry commented:

That workshop in 2008 prompted me to think more about e-governance and thereafter we started this e-governance activity through different development projects in ... [my ministry]. (Interview B, 4 July 2010)

The findings indicate a significant shift from the previous state where lack of knowledge was a major hindrance to ICT adoption (Imran, 2010). 